\title{
Se dice de mí. El autorretrato en la fotografía contemporánea argentina.
}

\section{Stefanini, Valeria [ver currículum del autor, docente de la Facultad de Diseño y Comunicación]}

\section{Resumen:}

Atravesamos una situación nueva, el autorretrato como género artístico siempre fue un tema predilecto para los artistas que elegían ser modelos de sus propias obras para abordar diferentes temas o simplemente para pintar la figura humana con un modelo que estaba siempre a mano. Hoy en día no hay que ser artista para poder realizar un autorretrato, el dispositivo fotográfico ha simplificado su manipulación, los costos han bajado y prácticamente todo el mundo posee o tiene acceso a una cámara con la que puede retratarse. Paralelamente el surgimiento de las redes sociales permite la exhibición pública de imágenes que de otro modo o en otras épocas no hubiesen salido del ámbito privado. Hoy todos podemos ser espectadores de las creaciones de una gran multiplicidad de personas que se comunican a través de las imágenes y crean contenidos por medio de éstas. Es una situación distinta que condiciona no sólo a los artistas sino también a los espectadores de estas obras, ya que estamos saturados de ver retratos personales, más allá de que no construyamos elementos de análisis para poder pensarlos.

Palabras clave:

autorretrato - fotografía contemporánea argentina - estudios de género - sociología del cuerpo.

Primero. Para empezar a pensar

El corpus de este ensayo exige una primera explicación. El concepto de autorretrato nos obliga a una especificación ya que pensar un corpus de investigación supeditado al tema es una elección tan válida como
Cuadernos del Centro de Estudios de Diseño y Comunicación Nº 64

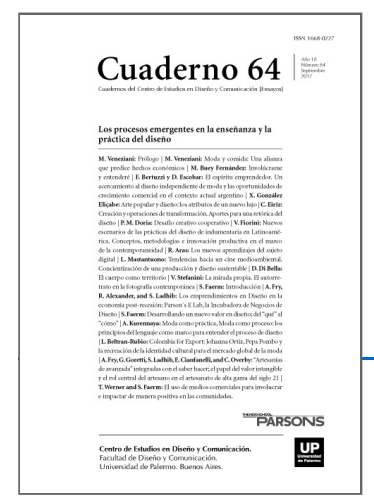

ISSN: 1668-0227

Los procesos

emergentes en la

enseñanza y la

práctica del diseño

Año XVIII, Septiembre 2017, Buenos

Aires, Argentina | 326 páginas

descargar PDF

ver índice de la publicación

Ver todos los libros de la publicación

compartir en Facebook

Esta obra está bajo una Licencia Creative Commons Atribución-NoComercialCompartirlgual 4.0 Internacional 
otra y no la única, pese a que la historia de la fotografía ha privilegiado este tipo de recortes. Joan Fontcuberta (1997) plantea que:

Todo mensaje tiene una triple lectura: nos habla del objeto, nos habla del sujeto y nos habla del propio medio.... Sea porque su propia naturaleza tecnológica le ha impelido a ello - como piensan algunos- o simplemente porque determinados usos históricos así lo han propiciado -como pensamos otros-, la fotografía ha vivido bajo la tiranía del tema: el objeto ha ejercido una tiranía casi absoluta. (p. 21)

El tema en la fotografía es lo que define este corpus pero es necesario decir como Fontcuberta que no es la única manera de hacer un recorte, y que este habla más del tipo de reflexión que se va a realizar que de la fotografía en sí misma. Este ensayo sigue la línea de una investigación iniciada hace ya unos años que centra su interés en los usos del cuerpo en el arte contemporáneo, en diferentes momentos en escritos publicados en otros cuadernos y espacios la mirada se dirigió a la fotografía de moda, a la performance y a la foto performance, hoy la intención es reflexionar acerca del autorretrato en la fotografía contemporánea argentina. Es por esto que la mirada se centra en el cuerpo y los usos que de este hacen los fotógrafos para hablar de si mismos, de la foto, y del lugar del artista y del fotógrafo en el arte y en la sociedad. ¿Qué es entonces un autorretrato? ¿Cuál es su relación con el retrato? ¿Cómo se han manifestado estos géneros en la historia del arte y de la foto en la Argentina? Carlos Cid Priego busca una aproximación que él llama definitoria:

...el retrato es la imagen de una persona, hecha por cualquier procedimiento, que de alguna manera establece relación de reconocimiento entre modelo y obra, ...siempre que persista al menos la intensión de mantener esa mutua dependencia. El autorretrato hay que considerarlo dentro de este concepto, con la diferencia de que en el retrato la acción es transitiva: hay un sujeto (artista), alguien que la recibe (modelo) y un complemento directo (obra), mientras que en el autorretrato equivale a una oración reflexiva porque la recibe el mismo sujeto que actúa y se identifica artista y modelo.

Este primer abordaje muy clásico y tradicional del autorretrato nos señala que debe haber identificación total entre el artista y el modelo. En una mirada más semiológica, que tuviera en cuenta al receptor de la obra, nos daríamos cuenta que durante largos periodos de la historia del arte el receptor de la obra también resultaba ser el mismo artista, ya que los autorretratos no eran realizados para ser vistos, consumidos y/o exhibidos por otro sino para sí mismos. Modelo, artista y receptor de la obra se unifican en una sola persona. Es recién en el arte contemporáneo que un artista empieza a pensar su autorretrato más allá de su uso personal y estas obras pueden ser parte del mercado del arte. Tampoco es suficiente esta definición ya que al hablar de fotografía no todos los artistas sacan ellos mismos las fotos al realizar un autorretrato. Para el autorretrato, en la pintura o en la escultura, tradicionalmente el artista ha debido valerse de un espejo o de una foto para poder plasmar por sí mismo la imagen capturada por esos dispositivos. El caso de la foto es levemente diferente, muchos artistas se valen de relojes que difieren el obturado o de cables para obturar a distancia. Pero muchos otros simplemente se valen de la ayuda de otro, la foto es sacada por un amigo, un espectador casual o un fotógrafo que facilita la toma. Por más que el artista no aparezca o que no aparezca su rostro, o que no saque él mismo la foto la obra puede seguir siendo considerada un autorretrato, es el caso por ejemplo de la obra Autorretrato del año 2000 en el que sólo vemos los pies de la artista rosarina Nicola Costantino manchados de sangre. No es la intención de este artículo realizar una cronología detallada de la evolución del retrato y del autorretrato en el arte occidental, baste decir que la producción, uso y comercialización de estas piezas artísticas ha estado siempre relacionada con el rol del artista en los distintos momentos, lugares y en los diferentes periodos de la historia. No siempre 
todo ha sido posible de ser representado, los temas tradicionalmente usados por los artistas se vinculan con prohibiciones y posibilidades delimitadas por la religión, la tradición, las modas y gustos, por el poder político y por el poder económico. La posibilidad y desarrollo del autorretrato se vincula necesariamente con el lugar que ocupan los artistas en la sociedad en los diferentes momentos de la historia. Si bien podemos rastrear autorretratos desde la antigüedad estos eran poco numerosos y poco significativos. Laura Malosetti Costa elabora en el catálogo de la exposición Yo, nosotros, el arte: el autorretrato en el arte argentino, que se presentó en el espacio de la Fundación OSDE en mayo de 2014:

Sin embargo, en los textos que nos han llegado de poetas, filósofos, retó- ricos, historiadores de la Antigüedad griega y romana, conocedores y admiradores de numerosas obras de pintura y escultura, la figura del artista visual no fue objeto de reflexión ni despertó particular interés. Escultores y pintores fueron considerados como trabajadores manuales (banausos), portadores de una serie de saberes y técnicas racionalmente organizados (techné), una actividad mucho menos prestigiosa que la de poetas, filósofos o músicos. No era el genio creador sino la pericia en la observación de la naturaleza y el manejo de los materiales lo que daba como resultado las obras que asombraban por su perfección y belleza. Se admiraron las obras pero no a sus creadores.

Posteriormente en el Renacimiento al revalorizarse el rol del artista y separarlo de la condición de artesano anónimo no sólo se genera la posibilidad de que el artista firme sus obras sino que se generaliza el uso del retrato y del autorretrato. En ese momento lo que se denominaba autorretrato estaba claro, se mostraba la figura del artista de la forma más mimética posible sirviéndose de uno o más espejos que permitían al artista el estudio de sus propios rasgos. David Le Breton entre sus estudios sobre el sociología y antropología del cuerpo escribe un libro titulado Rostros en el que rastrea cuál es la relación del hombre con su propio rostro y con su representación, indaga en los motivos por los que este se muestra o se oculta en diferentes momentos. Le Breton (2010) también entiende que es en el Renacimiento el momento en el que el retrato se constituye como un género significativo por los cambios sociales que se desarrollan y cita a Giorgio Vasari, el gran biógrafo de artistas del Renacimiento:

Vasari hace entrar sus biografías en los tiempos modernos. El interés por el retrato y por la biografía, dos signos espectaculares del nacimiento del individualismo. A los ojos de Vasari, el surgimiento del retrato es el indicio de la aparición de una mirada inédita sobre el mundo. (p. 35)

Evidentemente es un cambio con respecto a los tiempos anteriores. Considerar que algo tan efímero como los rasgos físicos de una persona determinada en un momento determinado de su vida o que una vida individual merecen perpetuarse por medio de una obra pictórica o literaria marca un cambio radical en nuestra concepción del individuo. Anteriormente hasta la Edad Media, los retratos que se realizaban ponían mayor hincapié en la representación de los atributos que de los rasgos característicos de la persona, ya que lo que se volvía importante era representar a esa persona por su rol social y recordarla ya sea como obispo, general, esposa, rey o papa. En el Renacimiento el sentido de la lectura no era lineal ni unívoco. Un autorretrato como el que Durero se realiza en 1498 nos lo presenta finamente ataviado y sin ningún atributo que permita identificarlo con su oficio de pintar, Durero no realiza la obra solamente para poner en exhibición su imagen de pintor joven, ni busca sólo la perpetuidad de sus rasgos, la obra es un manifiesto acerca de lo que el pintor considera que debe ser el lugar que ocupan los artistas en la sociedad. En el Renacimiento los artistas buscan no ser vistos como trabajadores manuales exclusivamente y es por esto que Durero se retrata con sus manos impecablemente cubiertas por guantes de cabritilla blancos. Nada en este retrato nos hace pensar en el sucio oficio de grabador o pintor. En un 
tenor semejante vemos retratos de Rubens que exhiben el lujo en el que se mueve el artista cuando pasea junto a su familia por espléndidos jardines, vistiendo todos lujosas ropas, poniendo de manifiesto la condición social y económica alcanzada por la práctica de su oficio. Otros retratos como los de Rembrandt o Van Gogh juegan roles más introspectivos, los artistas se usan como modelos cuando no hay nadie más o buscan mirarse en las obras y plasmar el dolor, la soledad o el sufrimiento. Autorretratos como los de Egon Schiele o los de Ernst Ludwig Kirchner rompen con la ansiada búsqueda de realismo y en la pincelada y el gesto se exhibe un estado de ánimo y la representación se acerca más a las características psicológicas que físicas de la persona. En cada caso podemos apreciar más o menos realismo, más o menos detalle, más o menos elementos que nos permitan contextualizar la obra, pero todos responden a una búsqueda de fuerte autorreferencialidad en la que el artista pone su cuerpo al problema que quiere abordar en la obra. Laura Malosetti Costa prosigue su análisis sobre el autorretrato:

Como manifiesto, como tributo a los maestros, como homenaje a los círculos y grupos de pertenencia y a los compañeros de ruta, como declaración de principios poniendo en juego el propio cuerpo, como gesto de dolor o de ironía vuelta sobre sí, los artistas salen a escena en sus obras no sólo mirándose en el espejo. El estilo se vuelve una máscara y el cuerpo aparece como soporte visible de decisiones estéticas largamente meditadas.

Pero qué pasa cuando ese cuerpo no aparece y la obra pierde la relación con un modelo que podemos reconocer fácilmente. Una obra de fuerte literalidad es el autorretrato de Leonado viejo de 1510 que da rostro a una figura en el imaginario colectivo, hoy en día es difícil pensar en el artista más allá de ese maravilloso dibujo. En contraposición un ejemplo en el que constatamos esta disolución de la imagen corporal son las obras en las que se representan los talleres de artistas sin que este aparezca como por ejemplo el caso de Fortunato Lacamera, Manuel Musto, entre otros, obras que hablan de ellos y en las que su presencia aparece y trasciende su cuerpo. En esta línea de pensamiento es interesante el trabajo de artistas como Florence Chevallier una fotógrafa nacida en 1955 en Casablanca. Ella misma nos relata el lugar que ocupa el cuerpo en su obra y que sucede cuando ya no lo vemos (Picaudé, 2004):

Durante un primer periodo, he estado muy presente en la imagen, seguramente porque no era consciente de mí misma. Ahora, muy consciente de mí misma, me ausento de la imagen. Mi recorrido consiste en ir de la representación de mi cuerpo a la representación de la ciudad en la que nací. Al fotografiar las fachadas de Casablanca y sus habitantes, exorcizo a plena luz los fantasmas de una historia personal que todavía habita estos lugares. (pp. 126-127)

Guadalupe Gaona es una fotógrafa argentina que logra en su proyecto Pozo de aire (2009) referir todo el tiempo y de modos diversos a ella misma. Hay textos que nos cuentan la historia de una niña, de la juventud en los 70 s en la Argentina, del gobierno militar, del destino de un joven peronista encarnado en su padre. Ella reconstruye una historia que quedó trunca cuando el gobierno militar desaparece a su padre, toda la reconstrucción de sí misma y de su identidad se realiza a través del recuerdo de las vacaciones con fotos viejas bien guardadas y con fotos nuevas, la memoria se une a la reconstrucción y de esa unión surge el sentido. Son trabajos que prueban que para hablar de una persona no es necesario mostrarla, que las vueltas que la encierran la definen tanto o mejor que una imagen, y que el camino más evidente no siempre es el único y a veces simplemente las definiciones clásicas no agotan las posibilidades de un tema. Entonces de repente la definición de autorretrato propuesta por Carlos Cid Priego ya no nos alcanza. El autorretrato ha trascurrido fuertemente unido al concepto de retrato y es un subgénero derivado de este. A partir del Renacimiento cuando el retrato cobra su fuerza, este 
género quedó profundamente estructurado. Era un género al servicio del mecenas y esto contribuyo a organizarlo y fomentarlo. Walter Benjamin en su texto Breve historia de la fotografía escrito en 1931 y publicado en la revista literaria alemana Die Literarische Welt en tres entregas reflexiona acerca de los primeros géneros que aborda la fotografía y de la importancia que cobra el retrato desde el primer momento, algunos de los datos que menciona dan cuenta del alcance de la foto al instalarse como el medio por el cual las personas van a buscar conservar su imagen y la de sus seres queridos.

Pero la verdadera víctima de la fotografía no fue la pintura de paisajes, sino los retratos en miniatura. Las cosas se desarrollaron tan rápido que ya hacia 1840 la mayoría entre los innumerables pintores de miniaturas se había hecho fotógrafo de profesión, al principio sólo ocasional, luego exclusivamente. (p. 93)

Pierre Sorlin menciona algunos datos con respecto a la rápida relación que establece la foto con el retrato, "Hacia 1860, Londres tenía no menos de doscientos estudios de retratos, unos cuarenta de los cuales estaban instalados en Regent Street, una de las arterias elegantes del centro de la ciudad". Sorlin luego mencionará que "Ias cuatro quintas partes de las fotos realizadas en el siglo XIX fueron retratos". (p. 34) Rápidamente la fotografía encontró un gran tema, una sociedad acostumbrada a entender el retrato como objeto de consumo de las élites económicas, se maravilló al poder acceder masivamente a la adquisición de una fotografía de sí mismos o de sus seres queridos. En un primer momento los largos tiempos de exposición que necesitaba una imagen para imprimirse en la película hacían que la pose fuera un ejercicio paciente y doloroso que se ayudaba con prótesis que permitían mantener el cuerpo erguido y quieto. Con el tiempo esto se fue solucionando, los tiempos se acortaron, las cámaras se simplificaron y por sobre todo bajaron sus costos, su peso y su tamaño, la fotografía paso de ser una técnica manejada por pocos a una manejada por todos, hoy en día todos fotografiamos y nos fotografiamos en cada momento de nuestra vida. No sólo no nos saturamos de representar una y mil veces las mismas imágenes sino que cada día lo hacemos nuevamente. Benjamin (2015) nos decía ya en 1931 que la foto no iba a renunciar a la representación del hombre,

Es evidente que esta nueva mirada tendrá menor cosecha allí donde, por lo demás, el asunto funcionaba más indulgentemente: en los retratos representativos, remunerables. Por otra parte, renunciar a los hombres es para la fotografía la renuncia más incumplible de todas. (p. 100)

Le Breton interpreta que la masificación del retrato fotográfico promueve en cada uno una fuerte conciencia de la singularidad:

El rostro entra socialmente en su fase democrática; llegará el día en que cada ciudadano posea uno, único, su bien más humilde y más preciado que encarna a su nombre. Incluso las personas más comunes acceden a ese antiguo privilegio, el de cualquier individuo, es decir, de todo hombre separado y consciente de su diferencia, exento de toda pertenencia al "nos otros". La fotografía, al personalizar al hombre, al distinguir su cuerpo sobre todo su rostro, aporta su contribución a la celebración del individuo. (p. 42)

Pero ¿para qué la acumulación cada vez mayor de estas fotografías? Baudelaire ya nos decía que el fin de la foto debe ser salvar del olvido a aquellas cosas que pueden perecer (o sea básicamente todo), podríamos agregar aquellos momentos que podemos llegar a olvidar, aquellas personas que en el futuro quizá ya no recordemos, etc. 
Joan Fontcuberta también piensa en el rol que cumplen todas estas imágenes:

La fotografía, en cambio, ese "espejo con memoria" según se llamaba al daguerrotipo, inmoviliza nuestra imagen para siempre, con todo lujo de detalles y la verdad como pátina. Una inmovilización y un aprisionamiento que nos acercará ineluctablemente a la idea de la muerte. (p. 30) Espejo con memoria es la expresión propuesta por Oliver Wendell Holmes en 1861 para calificar al daguerrotipo. (pp. 37-38)

Un espejo que nos congela en un momento, en una actitud y en una pose, que nos atrapa en una imagen que no necesariamente tiene algo que ver con nosotros. El retrato habla más del fotógrafo que del modelo, por más que desde el inicio del género los primeros fotógrafos trataron de pensar el procedimiento técnico de una forma objetiva, y se entendieron los retratos como un modo de captar al otro tal y como es, la realidad es que hoy ya nos hemos dado cuenta de la importancia de la mirada en la construcción de la fotografía y sabemos que no hay foto que no responda a un punto de vista, a la selección del momento preciso que es un atributo propio y particular de fotógrafo. El ser humano es un acontecimiento que sucede y que sólo podemos percibir de manera estática cuando es representado pictórica o fotográficamente, de ahí nuestro extrañamiento cuando vemos una foto (propia o ajena) y nos sentimos incapaces de reconocernos en la imagen (o reconocer al otro), somos nuestros gestos, somos en movimiento y el vernos detenidos nos extrapola de nosotros mismos, es el momento en que podemos tener conciencia del instante por fuera de la continuidad y eso no siempre sentimos que nos representa o no siempre nos resulta familiar. Cintia Mezza en su escrito El poder de la autorreferencia. Propuestas sobre los límites y las limitaciones del autorretrato en las artes plásticas después de la década del sesenta trata de pensar cuál es el lugar del concepto de género frente a la disparidad tan enorme de imágenes que analiza en su corpus,

Frente a la iniciativa de muerte del género -de Galienne y Pierre Francastel-, mi propuesta es la de pensar en el fenómeno de ampliación o expansión de los límites del género, especialmente en su variante autorretrato. Ciertas categorías, antes de extinguirse, pueden agotar sus posibilidades de elasticidad. Propongo entonces pensar en que estas categorías se expanden por sobre sus viejos límites frente a la pluralidad de manifestaciones del siglo XX. En la medida en que las manifestaciones artísticas se vuelven más autorreferenciales, el autorretrato, se reacomoda, redefine sus límites y especificidad, negocia terreno y sobrevive. Todos los procesos implican fisuras pero, no necesariamente extinción. (p. 5)

Entendemos que toda foto nos permite acercarnos a comprender un punto de vista del fotógrafo, pero no todas tienen eso como objetivo particular. Lo que vamos a tratar de pensar entonces al momento de organizar el corpus de reflexión es un concepto ampliado y flexible del género del autorretrato fotográfico. En algunas fotos aparece o no el fotógrafo, o hay algunas en las que no podemos reconocerlo y son sacadas o no por él. Lo que las convoca como representantes de autorretratos fotográficos es la convicción de que todas las obras lo que buscan es hablar profundamente, indagar acerca de sus autores, nos relatan un aspecto de su vida.

Maresca todo destino. El cuerpo como campo de batalla

Una foto es una huella. Pero, ¿una huella de qué? (Soulages, 2010, p. 18)

Es este concepto ampliado y flexible de autorretrato en el que podemos incluir aquellas obras que nos definen y nos describen al artista, obras en las que este aparece aunque no del mismo modo en el que Leonardo aparece 
en su ya mencionado dibujo. Tradicionalmente un artista al hacer su autorretrato se representaba de medio cuerpo, o más ocasionalmente de cuerpo entero, haciendo énfasis en su rostro, en la expresión de sus ojos y en sus manos. Siempre se ha considerado que los ojos y las manos demuestran la interioridad del ser humano y es por eso que los artistas suelen incluirlos en sus composiciones, con el fin de realizar un autorretrato que ahonde en la psicología del individuo y de ese modo contenga un carácter dramático y haga de cada uno de nosotros un ser único y singular. El rostro es el espacio mediante el cual hemos aprendido a reconocernos mutuamente y a nosotros mismos, hemos aprendido a entender sus diferencias y tenemos la capacidad de sacar conclusiones que nos organizan socialmente, es por eso que el autorretrato se vale del rostro ya que tradicionalmente a partir del Renacimiento uno de sus principales objetivos es la individualización del cliente que paga el precio al artista para quedar plasmado en el lienzo y justamente ser reconocido. Las obras que indagaremos a continuación nos exhiben a los artistas de un modo diferente, no son necesariamente las primeras que vienen a nuestro recuerdo cuando pensamos en un autorretrato y de ahí su interés y la riqueza teórica a que habilitan. Los artistas se presentan en acción con una obra claramente política, que pone en juego el lugar de la obra de arte, el lugar del artista, del cuerpo, del mercado, de la política en su definición más amplia. Son obras que buscan conectar y movilizar al espectador y que nunca jamás lo han dejado impávido. Para pensar sobre estos temas elegiremos la obra Vivo Dito de Alberto Greco de 1963, la serie El triunfo de la muerte de Oscar Bony de 1998 y Maresca se entrega todo destino de Liliana Maresca de 1993. Alberto Greco es un personaje multifacético de la escena artística de Buenos Aires en la década del 60, ha escrito libros, poemas, se dedicó a la pintura, dibujos, y performances como son los Vivo Dito, acciones que hubieran quedado invisibles para nosotros si no fuera por el registro fotográfico especialmente solicitado por el artista, ya que fueron realizadas en lugares alejados de los polos artísticos. Lo que Alberto Greco llamó Vivo Dito constituye una acción mediante la cual el artista señala algo o a alguien con una marca de tiza, de pintura o con un cartel. En la mayoría de las obras lo vemos a él mismo señalando lo que le interesa, llamando nuestra atención con carteles con su firma o con marcas de tiza blancas, son fotos realizadas por pedido de él a vecinos o amigos convocados a tal fin, como por ejemplo la artista Montserrat Santamaría, quién fue llamada por Greco para registrar estas acciones en la pequeña localidad española de Piedralaves. El Museo de Arte Contemporáneo de Rosario tiene en su colección algunas de las fotografías tomadas por Montserrat Santamaria. En la página oficial del MACRO se recuperan las palabras de la fotógrafa quién recuerda una de las acciones de Greco en la que participo todo el pueblo mientras él desenrollaba un rollo de papel pintado y escrito con el manifiesto Vivo Dito por las calles de Piedralaves

Gran Manifiesto Antimanifiesto Rollo Vivo-Dito, que Greco confeccionó en el marco de una puesta colectiva incluyendo a la población del lugar. Conformado por 200 metros de rollos de papel dibujados y escritos, este manifiesto objetual le sirvió al autor para bautizar el territorio elegido asignándole su sello. En los pliegos, se hallaban plasmados recuerdos de infancia, fotos, noticias del pueblo, letras de tango, notas periodísticas y anotaciones sobre arte. Apareció con un inmenso rollo de papel en blanco, que fue extendido por todas las calles, lo fue pintando él pero también con la colaboración de los niños que se volvían locos con su presencia. [...] [...] colaboraba todo el pueblo, desde la señora que sujeta el rollo de papel desde la ventana hasta la viejita que acaba de tender su ropa y se presta con una gran seriedad a colaborar en algo que para ella era lo más importante que le habían pedido en su vida.

Es en los Vivo Ditos en los que vemos como el artista fotografía, se fotografía o solicita a un tercero que realice la toma. La imagen del artista (aunque no siempre aparezca, ya que hay fotos en las que Greco no figura) se transforma en tema y material artístico de obras que distan totalmente del concepto de autorretrato tradicional 
acuñado por Cid Priego que se relaciona cercanamente con una definición de enciclopedia. Pero estas obras ponen en evidencia un tema central en la producción de Greco: la relación entre arte y vida, relación llevada al extremo cuando el artista se suicida luego de escribir en su mano la palabra FIN, en 1965 en la ciudad de Barcelona. La construcción de la obra no sólo involucra todos los aspectos de la vida del artista sino que se transforma en la vida misma. Estas obras podrían concebirse como fotoperformance y este concepto tampoco es algo que maneje pleno consenso en la definición. En un trabajo anterior (Stefanini, 2015) realizado sobre la fotoperformance pensábamos definiciones como las de Diane Taylor quien no concibe el registro como parte de la performance. Pensar la performance fotográfica implica problemas teóricos que no todos los investigadores resuelven de la misma manera. Diana Taylor (2012) aborda justamente la problemática de la performance y su relación con el registro y plantea:

Algunos especialistas aceptan el carácter efímero del performance, afirmando que el performance desaparece porque ninguna forma de documentación o reproducción logra capturar el carácter fugaz del acto EN VIVO. Peggy Phelan delimita la VIDA del performance al presente "El performance no puede ser guardado, grabado, documentado, sin que participe en la circulación de la representación (...) El ser del performance, como la ontología de la subjetividad propuesta aquí, deviene performance a través de la DESAPARICIÓN"1 . (p. 143)

En su sentido tradicional y más usado, performance es una acción que realiza o promueve un artista frente a un público. La performance se relaciona con el momento presente, se da en un instante, es irrepetible, es una experiencia de colaboración entre el artista y el espectador. Ninguna de estas características que pueden servir para definir la mayoría de las performance que conocemos nos sirve a la hora de tratar de comprender esas fotos que denominamos fotoperformance. Consideramos la performance fotográfica como uno de los tantos modos de realizar una performance, en este caso el artista se enfrenta a un sistema de registro de su acción ya sea una cámara fotográfica, de video o de grabación que va a constituirse como parte medular e indisociable de la realización. No es un sistema de registro ni de documentación de la acción realizada de manera aislada sino que debe ser parte medular estar incluida en la propuesta artística. En los tres casos que serán pensados, Greco, Bony y Maresca la fotografía cumple ese rol fundamental y es parte irrenunciable y final de la propuesta. Es por esto que no se las considerará como mero registro de una obra que sucedió sino que serán pensadas ellas mismas como la obra que sucede. Según Eduardo Costantini en el catálogo de la muestra que se realizó en el Malba en el 2007, "Bony es uno de los artistas latinoamericanos clave en la escena del arte de los últimos cuarenta años. También, un artista polémico y sorpresivo en cada una de sus propuestas y exposiciones". (p. 9) De todas las obras expuestas en esa enorme exposición de 2007 nos vamos a ocupar de un grupo de fotos en las que Bony aparece y se caracterizan por tener el vidrio fracturado por agujeros de disparos, estas series fueron realizadas entre 1993 y 1994. Andrea Giunta señala en el catálogo de la muestra cómo son estas obras que realiza Bony a su regreso de Italia, "El momento fuerte de su regreso comienza con una serie de fotografías introspectivas, biográficas, que lo colocan en el centro de su propia escena. Sobre esta imagen, su propio retrato, Bony va, literalmente, a disparar". (p. 24) Las fotos nos muestran autorretratos de Bony enmarcados en madera negra y con el vidrio agujereado por disparos de bala, organizados de manera metódica y calculada. En una de las obras (Corona de espinas) los agujeros se ubican en la frente de Bony formando algo así como la corona que llevó Cristo en la Pasión, en la obra Cruz del diablo las balas dan forma a una cruz en la frente. Estas obras nos hablan de violencia, muerte y dolor con una fuerte carga de sentido religioso. En otras obras aparece la sombra del artista también disparada, el artista de espaldas vestido con un traje negro en una construcción del espacio que es una clara cita a la obra de Magritte y aparece también baleado. Varias fotos de 
la serie nos muestran al artista (siempre en su traje negro) en el aire justo en el momento del salto con el cable del obturador en la mano, y el espectador no puede dejar de hacer la relación entre disparar una cámara y un arma, ya que los dos tipos de disparos están presentes en la obra. Bony dice "Toda la violencia que genera y ha generado este país tiene que ver con lo que hago". Tiene que ver con lo que hace y tiene que ver con él, impacta directamente en él, el artista pone su cuerpo en escena para ejemplificar el modo en el que se involucra con las cosas, cada acto de violencia es una agresión ejercida directamente contra él, es un disparo. Un poco antes desde 1992 había sido el momento de la Serie de la memoria. Esta obra son montajes en los que Bony utiliza fotos antiguas propias y de su familia a las que vuelve a fotografiar sosteniéndolas con sus manos que quedan a la vista, las enmarca y las exhibe junto a objetos reales como camisas, trípodes, palas, etc. Son secuencias de memorias construidas para ser nuevamente miradas a la luz del presente. El triunfo de la muerte en cambio usa fotos actuales sacadas para la serie y no recurrirá a las fotos antiguas. Andrea Giunta nos dice que:

Bony, al realizar y exponer estos autorretratos plantea una posesión de la imagen de sí mismo, de la que él dispone y que también expone a la mirada del público. La relación entre el retrato y la persona no deja de estar regulada por cierta magia. Las fotografías que nos legó le dispensan un grado de realidad: son imágenes portadores de un poder porque nos recuerdan a una persona cuyo lugar ocupan. (p. 33)

En la serie Suicidios de 1993/1996 hay tres obras tituladas El juicio final. Suicidios I, II y III en las que me gustaría detenerme. En el primer Suicidio vemos una foto color sepia, borrosa que nos muestra a Bony joven mirando directo al espectador y sobre su pecho y su cara aparecen los agujeros de los disparos que posteriormente un Bony adulto hará sobre el vidrio. La foto número dos de la serie nos lo muestra adulto y mirando fieramente al espectador mientras sostiene en su mano el disparador de la cámara de fotos para sacar la foto a distancia. La tercera nos lo muestra igualmente feroz pero ahora con el arma en la mano. Es evidente la reflexión acerca del tiempo que transcurre, la sociedad, la violencia, y el lugar del arte y del artista. Son las reflexiones que surgen en todas las obras de Bony que hemos mencionado. Marcelo Pacheco menciona en el mismo catálogo de la exposición que:

El uso del término 'fotografía` es escaso como descriptor técnico y autoritario en su clausura de sentidos. El soporte que fabrica el artista entre 1993 y 1994, y que se convierte en su principal medio de expresión, es un dispositivo complejo que comprende fotografía y vidrios baleados y enmarcados. Un nudo de materiales y gestos que confirman el carácter único y la cualidad temporal de las obras. (p. 16)

Pacheco señala como un elemento importante el marco. Dentro de las distintas series en las que encontramos vidrios baleados hay una titulada De amor y violencia que utiliza marcos antiguos, dorados y con molduras, otras series llevan un sencillo marco de madera y de líneas rectas, algunos en negro y otros en dorado. El marco es el límite que sostiene esa estructura fragmentada y de aspecto frágil que es el vidrio baleado que genera en el espectador la sensación de que está próximo a despedazarse y hacerse añicos contra el suelo si no estuviera atrapado entre varillas. Cuando Pacheco se refiere a que "fotografía" es un término que no define completamente la obra, que no da cuenta de ella y nos abre a pensar en diferentes sentidos. En primer lugar una foto se caracteriza por romper con el concepto que diferencia el original de la copia, todas las copias de un negativo son fotos originales. La intervención sobre una copia la hace obra única, se rompe con la reproductividad lo que modifica totalmente el sentido de lo fotográfico. Liliana Maresca es una artista que surge en la esfera local en la década del 80 con la vuelta a la democracia. Un momento en el que uno de los grandes 
temas era justamente la recuperación de la libertad. Libertad de expresión, libertad sexual, libertad de acción. En un ámbito así el arte en colaboración o grupal, la performance, las acciones e instalaciones van a ser el recurso elegido por muchos artistas para plantearse y plantear problemas contemporáneos del arte y de la sociedad. En octubre de 1993 en la revista de relatos eróticos El Libertino se publica Maresca se entrega todo destino. Andrea Wain en la página de estudios sobre performances Vivo Dito relata quienes participaron de la producción "Alejandro Kuropatwa (fotografía), Sergio De Loof y Sergio Avello (vestuario y maquillaje). Publicación registrada bajo el copyright de Fabulous Nobodies, marca de Roberto Jacoby y Kiwi Sainz". Liliana Maresca, al igual que Greco, contó con la ayuda de fotógrafos que realizaron las fotos de sus performances, Alejandro Kuropatwa, Marcos Lopéz o Adriana Miranda. Las fotos son parte de una publicidad a doble página que salió publicada en la revista, con una serie de catorce fotografías tomadas que registran a Maresca en poses provocativas. Maresca aparece vestida o desnuda jugando con un osito de peluche. La obra tiene un texto que le da título: Maresca se entrega todo destino, el teléfono de ella, y los créditos en los que dice los siguiente, "La escultora Liliana Maresca donó su cuerpo a Alex Kuropatwa -Fotógrafo-, Sergio De Loof -Trend Setter-, y Sergio Avello Maquilladora- para este maxi aviso donde se dispone a todo". Más de trescientas personas llamaron al número ofrecido en la publicidad, con cuatro de las cuales la artista se reunió. Supongo que la identificación de Maresca como una escultora hizo que muchas personas se dieran cuenta de que no era una llamada a una línea Hot común y percibieran que la publicidad era parte de algo más aunque no todos los usuarios de la revista se detuvieran a pensar en ello. En los tres casos que estamos usando para pensar el concepto se sostiene y cobra fuerza de manera muy vinculada con la cantidad de imágenes que aparecen ante el espectador. En los tres casos los autores funcionan con series que repiten el concepto hasta darle forma. La propuesta de Maresca es una publicidad compuesta por catorce fotos en las que se va dando cuenta del movimiento y permite a la artista jugar sensualmente con su cuerpo y variar las poses. La obra de Maresca es específicamente una serie ya que en la misma obra aparecen todas las fotos, todas las poses, todos los momentos. Los tres proyectos se sostienen por medio de la serialidad con la que fueron trabajados pero sólo el de Maresca lo explicita tan claramente. La decisión de Maresca de publicar la obra en una revista y de hacerlo como si fuera una publicidad cualquiera la relaciona con un público que no necesariamente está vinculado con el arte o por lo menos no está esperando hacer una reflexión acerca del arte contemporáneo en su consumo de una publicación erótica, esto la acerca a Greco con sus performances en Piedralaves, ya que la gente que interviene y se transforma en público de estas acciones no está buscando ser parte de una obra de arte, ni está al tanto de los debates teóricos del arte contemporáneo sino que se incorporan a las acciones de Greco en medio de su cotidianeidad, de manera lúdica y casual. El contexto en el que se muestran da forma y contenido a estas obras, pero al mismo tiempo deben ser sacadas de ese contexto al momento de ser pensadas. Cintia Mezza en el artículo mencionado piensa acerca de esos autorretratos en los que la imagen física del artista no aparece en primer plano y de manera contundente:

Se trata precisamente de representaciones que no son idénticas a sus artistas pero si, son idénticas a sí mismas, a la producción de aquellos artistas. De esta manera, no será el rostro lo que encontremos en estos autorretratos, pero serán representaciones que reúnan las características típicas del estilo del artista o de su factura, en lo técnico o en lo matérico, por lo tanto, la autorreferencialidad se conserva. (p. 7)

A esto nos referimos en la mayoría de las obras de los tres casos, el autorretrato es el modo en que un artista elige para hablar de sí mismo, para mostrarse ante el otro, elige una manera de definirse que no es necesariamente usando su imagen física, no es necesariamente su rostro, y si usa su cuerpo, como en los tres 
casos que hemos elegido, lo obliga a decir algo, lo usa como una manera de poner en evidencia un concepto. Las obras no nos cuentan sólo como son ellos, recorren otro camino, más sinuoso y circular, en el que el artista se dona (usando la expresión de Maresca) para hablar del arte y de la vida.

Notas

1. En mayúsculas en el original.

Bibliografía

Benjamin, W. (2015). Breve historia de la fotografía. En Estética de la imagen. Buenos Aires: la marca editora. Cid Priego, C. Algunas reflexiones sobre el autorretrato en file:///D:/a\%20VALE/a\%20Fotogra fia\%20y\%20moda/Autorretrato/Dialnet-AlgunasReflexionesSobreElAutorretrato-72636. pdfn (10/2/2016) Fontcuberta, J. (1997). El beso de judas. Fotografía y Verdad. Barcelona: Gustavo Gili S.A. Gaona, G. (2009). Pozo de aire. Buenos Aires: Ediciones Senda VOX. Le Breton, D. (2010). Rostros. Ensayo antropológico. Buenos Aires: Letra Viva. Malosetti Costa, L. Yo, nosotros, el arte: el autorretrato en el arte argentino. En http://arte. elpais.com.uy/yo-nosotros-el-arte-el-autorretrato-en-el-arte-argentino/\#.VsjGuLThDDc

Mezza, C. El poder de la autorreferencia. Propuestas sobre los límites y las limitaciones del autorretrato en las artes plásticas después de la década del sesenta. En www.caia.org.ar/ docs/Mezza.pdf Picaudé, V. y Arboizar, P. (2004). La confusión de los géneros en fotografía. Barcelona: Gustavo Gili S.A. Sorlin, P. (2004). El "siglo" de la imagen analógica. Los hijos de Nadar. Buenos Aires: la marca editora. Stefanini, V. (2015). Alberto Greco, Los vínculos entre la foto y la performance. En http://fido.

palermo.edu/servicios_dyc/catalogo_investigacion/detalle_proyecto.php?id_proyecto =3417\&titulo_proyectos=Alberto\%20Greco.\%20Los $\% 20$ v $\%$ EDnculos $\% 20$ entre $\% 20$ la\%20foto\%20y\%20la\%20performance. Soulages, F. (2010). Estética de la fotografía. Buenos Aires: la marca editora. Taylor, D. (2012). Performance. Buenos Aires: Asunto Impreso Ediciones.

\section{Catálogos}

Lauria, Adriana. (febrero 2008) Liliana Maresca. Transmutaciones. Museo Municipal de Bellas Artes Juan B: Castagnino de Rosario. Oscar Bony. El Mago. Obras 1965 / 2001. MALBA 2007. Buenos Aires.

Páginas de artistas

http://www.florencechevallier.org/indexflash.html http://www.vivodito.org.ar/node/33

Abstract:

We have crossed a new situation where the self-portrait as an artistic genre has always been a favorite subject for artists who chose to be models of their own work in order to address different topics or to simply paint the human figure with a model that was always on hand. Today, one does not need to be a professional artist to create a selfportrait; photographic devices are simplified, associated expenses are greatly reduced, and almost everyone owns (or has access to) a camera to portray themselves. Additionally, the emergence of social media allows the public to display images that would not otherwise be shared a few years ago. Today, we can all view 
the artistic creations made by a great number of people who communicate personally through these images. It is a new situation that affects not only artists but also viewers of these works, as viewers are saturated with viewing personal portraits without applying thoughtful, analytical elements.

Key words:

selfportrait - contemporary Argentina's photography - genre studies - body sociology.

\section{Resumo:}

O auto-retrato como gênero artístico foi sempre um tema predileto entre os artistas que elegiam ser modelos de suas próprias produções para abordagem de temas diversos. Hoje não é necessário ser artista para fazer um auto-retrato, o dispositivo fotográfico simplificou sua manipulação, os custos desceram e as pessoas têm acesso a uma câmara fotográfica para poder-se retratar. Em paralelo, o surgimento das redes sociais permite a exibição pública de imagens que de outra maneira ou em outras épocas não tinham saído do âmbito privado. Hoje todos podemos ser espectadores das criações de muitas pessoas que se comunicam através das imagens e criam conteúdos por meio delas. É uma situação diferente que condiciona não somente aos artistas senão também aos espectadores destas obras, já que estamos saturados de ver retratos pessoais além do que não construamos elementos de análise para poder pensá-lo.

Palavras chave:

auto-retrato - fotografia contemporânea argentina - estúdios de gênero - sociologia do corpo.

Se dice de mí. El autorretrato en la fotografía contemporánea argentina. fue publicado de la página 153 a página167 en Cuadernos del Centro de Estudios de Diseño y Comunicación № 64 